\title{
A Note on Currency
}

DURING 2008 AND 2009, the period of research, the South African rand fluctuated: on average it was equal to $\mathfrak{E} 0.07$ GBP and US $\$ 0.12$.

That is, $\mathrm{R} 10=0.70$ pence or US $\$ 1.20 ; \mathrm{R} 100=\mathfrak{E} 7$ or US $\$ 12.00$. 


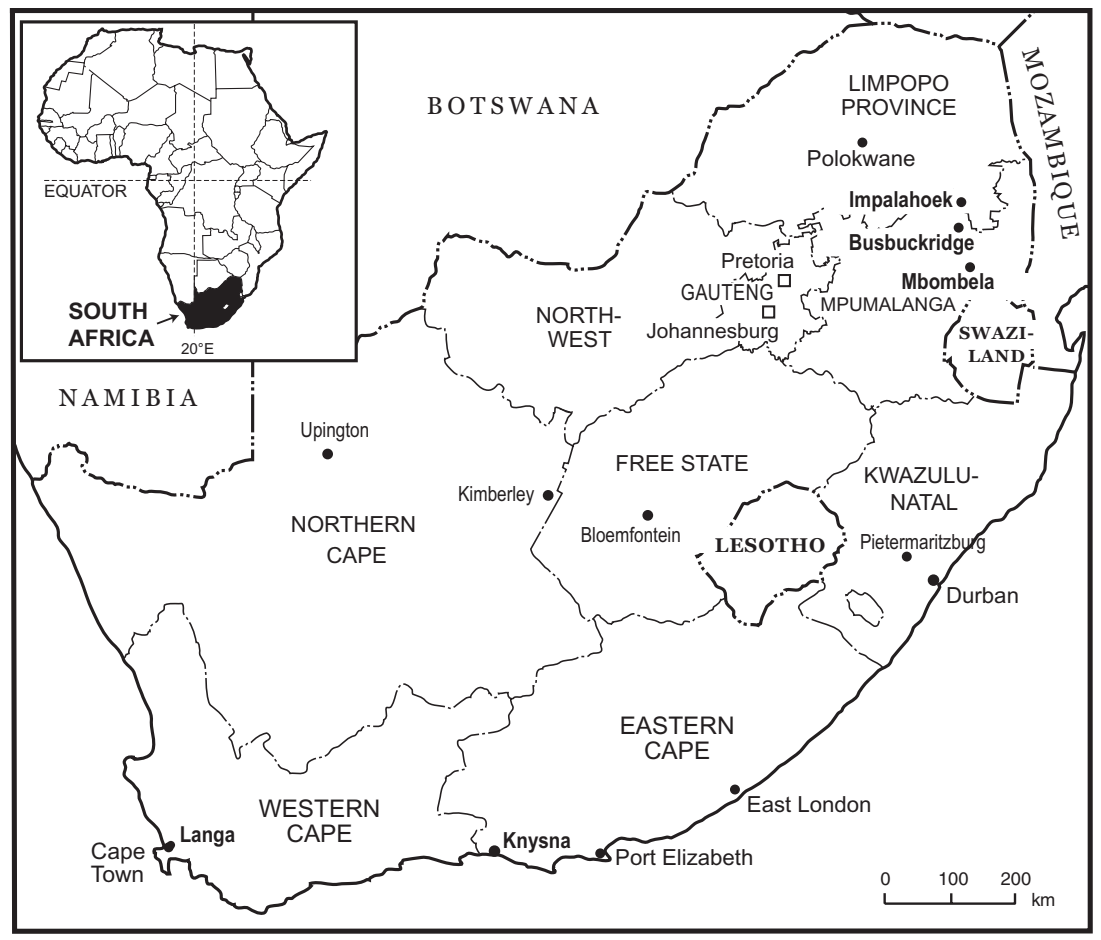

Map 1 Map of South Africa showing field sites and places mentioned in the text Source: Drawn by Wendy Phillips. 


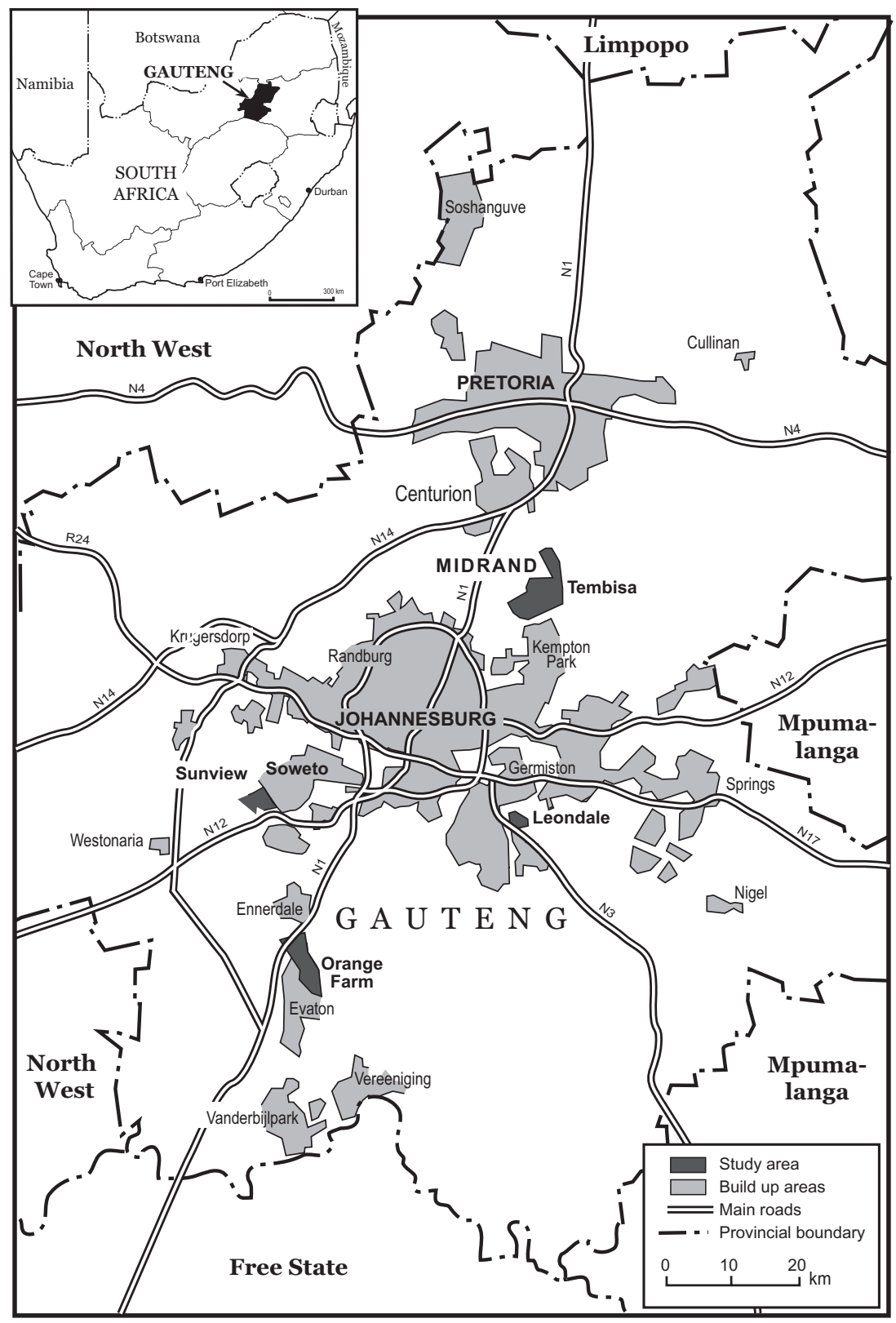

Map 2 Map of Gauteng showing field sites and places mentioned in the text Source: Drawn by Wendy Phillips. 
